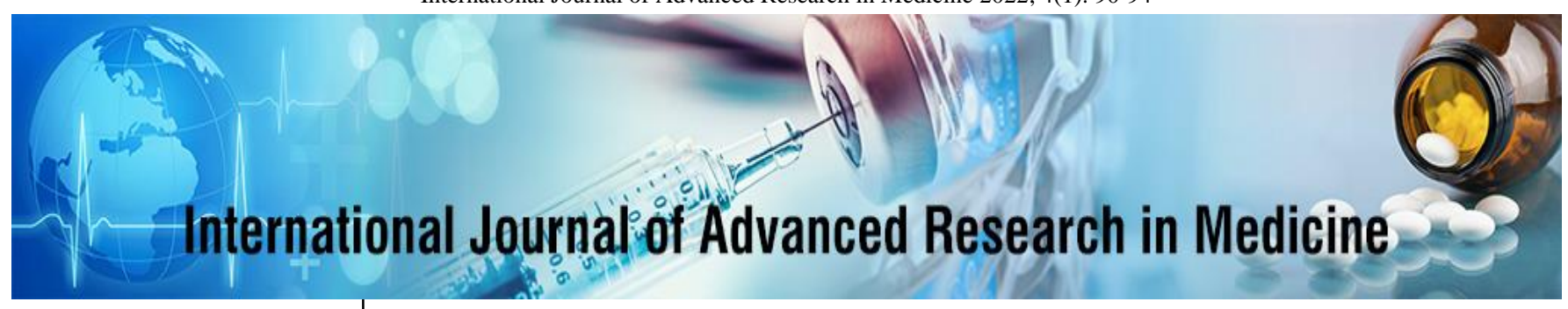

E-ISSN: 2706-9575

P-ISSN: 2706-9567

IJARM 2022; 4(1): 90-94

Received: 10-11-2021

Accepted: 12-12-2021

Dr. Srikanth Reddy

Department of ENT, Assistant Professor, TRR Institute of

Medical Sciences, Patancheru, Sangareddy, Telangana, India

Dr. Rakesh Pradhan Department of Pathology, TRR Institute of Medical Sciences, Patancheru,

Sangareddy, Telangana, India

Corresponding Author: Dr. Rakesh Pradhan Department of Pathology, TRR Institute of Medical Sciences, Patancheru,

Sangareddy, Telangana, India

\section{Clinical study of benign lesions of larynx}

\author{
Dr. Srikanth Reddy and Dr. Rakesh Pradhan
}

DOI: https://doi.org/10.22271/27069567.2022.v4.i1b.342

\begin{abstract}
Background: The significance of benign lesions of the larynx lies in the importance of its function in speaking and the contribution of the voice to one's identity. Inadequate voice is a social and professional disadvantage. Although rarely life threatening.

Objectives: To study benign lesions of larynx.

Methods: A total number of 64 patients were studied, A thorough history of all patients included in the study was taken with respect to the presenting symptoms and their duration. The treatment advised to the patients was either conservative medical therapy and/or surgical therapy (micro laryngeal surgery). All the patients underwent micro laryngeal surgery except those patients with vocal nodules. They were advised speech therapy for 3 months, if not resolved with speech therapy underwent micro laryngeal surgery.

Results: There were varied causes for the development of benign lesions of larynx in which chronic vocal misuse was predominant cause in benign vocal fold lesions. It shares $75 \%$ of the incidence. Reasons for chronic vocal misuse is related to the occupation. The commonest site of origin of lesions was from true vocal cords. Next commonest were false cords, arytenoids and interarytenoid regions. In the study group, only $18.3 \%$ patients got complete relief with voice rest and vocal rehabilitation, $82.7 \%$ patients required surgery, which included microlarygoscopy and end laryngeal surgery.

Conclusion: The benign laryngeal lesion produces symptoms which can vary from mild hoarseness to life-threatening stridor, creating a lot of mental and emotional tension in the patient and the family. Early diagnosis of the lesions can lead to effective management and good recovery.
\end{abstract}

Keywords: chronic vocal abuse, hoarseness, benign neoplasms, larynx

\section{Introduction}

Benign neoplasms of the larynx constitute an interesting array of lesions and have been defined as "An abnormal mass of tissue in the larynx, the growth of which exceeds and is uncoordinated with that of normal tissue and persists in the same excessive manner after cessation of stimuli which evoked the change ${ }^{[1]}$. The significance of benign lesions of the larynx lies in the importance of its function in speaking and the contribution of the voice to one's identity. Inadequate voice is a social and professional disadvantage. Although rarely life threatening, these lesions cause tremendous alteration in daily living and should not be underestimated. These lesions can have a significant influence on vocational, social and emotional adjustment of patients ${ }^{[2]}$. Physicians particularly otolaryngologists, usually are first persons to be approached when voice sounds abnormal. Hoarseness of voice is one of the commonest symptoms in otolaryngological practice and is invariably the earliest manifestation of a large variety of conditions directly or indirectly affecting the voice apparatus. "Hoarseness is a symptom of utmost significance. Its importance derives from the deplorable fact that though benign lesions are numerically more common cause of hoarseness of voice than malignant diseases, opportunity for the cure has often been lost by delay under a benign diagnosis".

During the last decade, there has been a tremendous advancement in laryngology. Micro laryngology and Endo laryngeal microsurgery, as well as the recently introduced fibro-optic telescope, have reduced our dependence on mirror examination and have improved our diagnostic ability. These changes have already induced considerable rethinking of the earlier concepts of certain laryngeal conditions, such as those associated with epithelial hyperplasia.

\section{Materials and Methods}

Study Setting: This study is conducted at Govt. Ent Hospital, Koti, Hyderabad. 
Sample size: A total number of 64 patients were studied.

Inclusion criteria: Hoarseness/change in voice; difficulty in breathing; foreign body sensation in the throat; pain on speaking and fatigue of voice; common cold and the findings were correlated with indirect laryngoscopy.

Exclusion criteria: Patients with clinical diagnosis of malignancy of larynx; all cases with acute inflammatory lesions; patients with speech defect due to central nervous system (CNS) lesions; patients with oral and pharyngeal pathology; and cases with nasal and nasopharyngeal pathology.

All the patients included in the study were questioned about age, sex, occupation, socioeconomic status and area of residence. History of all patients included in the study was taken with respect to the presenting symptoms and their duration. Investigations included routine blood investigations, urine microscopy, radiological investigations [X-ray paranasal sinuses, X-ray chest (postero-anterior view), plain X-ray (neck- lateral view)], direct laryngeal endoscopy, followed by histopathological examination. The treatment advised to the patients was either conservative medical therapy and/or surgical therapy (micro laryngeal surgery). All the patients underwent micro laryngeal surgery except those patients with vocal nodules. They were advised speech therapy for 3 months, if not resolved with speech therapy underwent micro laryngeal surgery.

In case the patient was advised surgical treatment, preoperative assessment of the patient was done which included evaluation and correction of nasal and sinus infections and oral hygiene. Postoperative management included complete voice rest for one week followed by gradual resumption of voice in order to resume the normal function of the vocal cords until three weeks. After three weeks, when the healing appeared to be complete, a regime of gradual talking was started. The patient was instructed to remain silent except for a specified period of time every day and then to gradually increase the frequency and duration of these periods. This module was continued for two weeks after the surgery and then the patient was advised to be back to his normal regimen. All patients underwent postoperative speech therapy. Along with this regime, the patient was also advised steam inhalations, prescribed proton pump inhibitors for three months to reduce gastric reflux and to avoid extremely hot and cold foods, foods with strong seasonings, exposure to air pollutants, smoking, tobacco, alcohol and coughing and clearing the throat. Frequent follow up of these patients was done using 45 degree endoscope to visualize the larynx (especially the vocal folds) and assess the voice quality.

Statistical Analysis: Statistical analysis was done using SPSS 21 software. The data was presented in the form of table with percentages.

\section{Observation and Results}

Table 1: Distribution based on Gender and age group

\begin{tabular}{|c|c|}
\hline Gender & Incidence \\
\hline Male & $43(67.18 \%)$ \\
\hline Female & $21(32.8 \%)$ \\
\hline \multicolumn{2}{|c|}{ Age Distribution } \\
\hline 0-10 years & 3 \\
\hline $11-20$ years & 7 \\
\hline 21-30 years & 13 \\
\hline 41-40 years & 19 \\
\hline 51-50 years & 17 \\
\hline & 5 \\
\hline
\end{tabular}

Out of 64 cases that were studied 43(67.18\%) were males and $21(32.8 \%)$ were females, showing Male preponderance. Out of 64 , there were 4 pediatric cases ageing below 12 years. In our study, males were seen to predominate over females with a ratio of 2.04: 1 (i.e., 43 males to 21 females.
The youngest patient in our study was one and half year old; the oldest being 60 years. The maximum number of cases were seen in the age group between 31 and 40 years (19cases).

Table 2: Distribution based on Etiology and Precipitating factors

\begin{tabular}{|c|c|}
\hline Etiology & Percentage \\
\hline Chronic vocal misuse / abuse & $50 \%$ \\
\hline Human papilloma virus & $17.18 \%$ \\
\hline \multicolumn{2}{|c|}{ Chronic infectious diseases } \\
\hline \multicolumn{2}{|c|}{ Precipitating factors/ habits } \\
\hline Chronic voice misuse/abuse & $64 \%$ \\
\hline Smoking & $36 \%$ \\
\hline Alcohol & $36 \%$ \\
\hline Frequent throat clearing & $40.6 \%$ \\
\hline
\end{tabular}

There were varied causes for the development of benign lesions of larynx in which chronic vocal misuse was predominant cause in benign vocal fold lesions. It shares $75 \%$ of the incidence. Reasons for chronic vocal misuse is related to the occupation. Out of 43 male patients, 18 were smokers. None of female patients were smokers.
Out of 50 cases of benign lesions of vocal fold (vocal polyps, nodules, cysts) precipitating factors include chronic vocal misuse/abuse (64\% of cases), smoking and alcohol (36\% of cases) and regional sinus sepsis ( $40.6 \%$ of cases) as suggested by frequent throat clearing. 
Table 3: Distribution based on percentage of cases with benign lesions of larynx

\begin{tabular}{|c|c|}
\hline \% of cases of benign lesions of larynx & Frequency \\
\hline vocal polyps & $31(48.43 \%)$ \\
\hline vocal nodules & $15(23.43 \%)$ \\
\hline laryngeal papilloma & $11(17.18 \%)$ \\
\hline vocal cysts & $4(6.25 \%)$ \\
\hline TB Laryngitis & $2(3.12 \%)$ \\
\hline Fungal laryngitis & $1(1.56 \%)$ \\
\hline
\end{tabular}

Most of the cases in our study group had vocal cord polyps $31(48.43 \%)$, vocal nodules $15(23.43 \%)$ Papilloma's $11(17.18 \%)$, Vocal cysts $4(6.25 \%)$, tuberculosis of larynx 2(3.12\%), Fungal laryngitis1(1.56\%), However, neoplastic lesions like, adenoma, chondrama and other non-neoplastic lesions like intubation granuloma, contact ulcer granuloma, reinke's oedema were not encountered.

Table 4: Distribution based on Site of involvement

\begin{tabular}{|c|c|}
\hline Site of Involvement & Frequency \\
\hline Right vocal cord & 21 \\
\hline Left vocal cord & 17 \\
\hline Bilateral & 12 \\
\hline
\end{tabular}

The commonest site of origin of lesions was from true vocal cords. Next commonest were false cords, arytenoids and interarytenoid regions Out of 11 cases of laryngeal papilloma commonest site of involvement were vocal folds, false cords, anterior commissure, sub glottis and laryngeal surface of epiglottis. Out of 2 cases of TB laryngitis. Commonest site of involvement is posterior part of vocal cords, arytenoid and interarytenoid region. In cases of vocal cord polyps, the commonest site was at junction of anterior one -third and middle third. Out of 31 vocal cord polyps, 17 was on right vocal cord and 14 were on left vocal cords. Out of 15 cases of vocal nodules, 12 were bilateral, in three cases it was unilateral. Speech therapy failed in these three cases.

Table 5: Distribution based on Management

\begin{tabular}{|c|c|}
\hline Management & Frequency \\
\hline Surgery (MLS) & $82.3 \%$ \\
\hline Conservative Management (Speech therapy) & $18.3 \%$ \\
\hline
\end{tabular}

Out of the 60 patients in the study group, only $18.3 \%$ patients got complete relief with voice rest and vocal rehabilitation, all belongs to vocal nodules; $82.7 \%$ patients required surgery, which included micro-laryngoscopy and endo-laryngeal surgery.

Table 6: Distribution based on type of lesion and recurrence

\begin{tabular}{|c|c|c|}
\hline Type of Lesion & $\begin{array}{c}\text { No. of } \\
\text { Cases }\end{array}$ & Recurrence \\
\hline Vocal Polyp & 31 & 1 \\
\hline Vocal Nodule & 15 & 1 \\
\hline Vocal Cyst & 4 & 0 \\
\hline Laryngeal Papilloma & 11 & 3 (required repeated debulking) \\
\hline
\end{tabular}

There was one recurrence in cases of vocal polyps and no recurrence in cysts during the period of observation. Reason for recurrence is that the patient was not committed to post operative voice rehabilitation. One case of laryngeal tuberculosis was partially free of symptoms because of noncompliance of patient. Out of 15 cases of vocal nodules, voice therapy failed in three patients. They underwent micro laryngeal surgery. One case of vocal nodule (spindle nodule) recurred. Out of 11 cases 3 cases of laryngeal papilloma's required repeated debulking at a gap of one year during the period of observation. All cases underwent tracheostomy prior to repeated debulking. Out of 11 cases of laryngeal papilloma

\section{Discussion}

The results in this study are in concurrence with most of the reviewed studies. The sex incidence, with male preponderance, is similar to other studies. Higher incidence of benign lesions of the larynx were reported among males as compared to females with a M:F ratio of $2.04: 1$ in this study. This is in accordance with study conducted by Pawan Singhal et al. ${ }^{[3]}$.

Higher incidence of benign lesions was observed in professional voice users, the highest incidence was observed in housewives followed by laborer/farmers among the nonprofessional voice users. These observations are in accordance with those of Strong and Vaughen ${ }^{4}$ and Baitha $e t$ $a l .{ }^{[5]}$ This may be likely because of the misuse or abuse of voice.

In this study, maximum number of patients have vocal cord polyps followed by vocal nodules, Papilloma, cyst. These findings indicate preponderance of non-neoplastic tumors over neoplastic tumors, confirmed by histopathological examination and have been supported by the elaborate classification given by Myerson and revised by Friedmann $[6,7]$.

With regards to the site of origin of the benign tumors, true vocal cords were found to be the commonest site for the origin of all non-neoplastic tumors viz. polyps, nodule and cysts. These findings are in accordance with the findings reported by Hegde et al. ${ }^{[8]}$ Vocal polyps and vocal nodules which together constituted majority of cases were found at the junction of anterior $1 / 3 \mathrm{rd}$ and posterior $2 / 3 \mathrm{rd}$ of the true vocal cords. This is because the mechanical force of vibration is most intense at this site. Overall, right vocal cord was involved more than left vocal cord. This is similar to the study conducted by Wani et al. ${ }^{[9]}$.

Hoarseness of voice was found to be the most prominent and presenting feature of these lesions in this study followed by throat pain/irritation, cough, foreign body sensation in throat, difficulty in breathing and difficulty in swallowing. This is in concordance with study conducted by previous studies ${ }^{[10,11]}$.

Surgical treatment was the treatment of choice in majority of the cases studied $(82.7 \%)$ and voice rest and rehabilitation sufficed in the remaining $18.3 \%$ cases. Of the different modes of management mentioned in the literature viz. medical, physical, immunological and surgical, the last one remains the standard treatment of choice in all types of tumors and in all age groups. Voice rest and vocal rehabilitation remains the treatment of choice applicable to early stages of vocal nodule and in preventing the recurrence of benign tumor (polyps, cysts etc.) postoperatively. Chagnon et al. ${ }^{[12]}$ However, it has been advised that surgical treatment of benign vocal fold lesions of the larynx must invariably be followed by post-operative voice correction therapy, otherwise recurrences are liable to occur ${ }^{[13]}$.

Management of vocal cord polyps were by microlarygoscopy and excision biopsy by micro flap 
technique followed by voice rest for 7 days and speech therapy. There was one recurrence in cases of vocal polyps Reason for recurrence is that the patient was not committed to post operative voice rehabilitation

Vocal nodules were treated initially by educating the patient regarding proper vocal hygiene and the importance of adequate hydration for vocal fold function, i.e. by drinking water, use of steam inhalations and avoiding excessive amounts of drinks containing caffeine, i.e. coffee, tea and colas; smoking cessation, reducing alcohol and social drug consumption (particularly spirits, cannabis and cocaine) and avoiding exposure to fumes, dust and dry air; diet and reflux reduction, for example avoiding eating late at night, large or fatty meals. Avoidance of vocal abuse, misuse, and overuse in the form of Voice therapy by a highly skilled voice therapist for a minimum of 3 months is advised. Surgery was done in three cases out of thirteen by using microdissection techniques where nodules persisted and the voice remained unacceptably impaired from the patient's perspective, even after an adequate trial of voice therapy. This is followed by relatively short period (7 days) of postoperative voice rest and speech therapy. Out of 15 cases of vocal nodules, voice therapy failed in three patients. They underwent micro laryngeal surgery. One case of vocal nodule (spindle nodule) recurred.

Management of vocal fold cyst was primarily surgery using micro flap method following strict voice rest for 1 week-Out of four cases one case was done by lateral micro flap technique. All cases had complete recovery without any recurrence. By following this regime in the present study in which 31 cases of vocal polyps, 3 nodules and 4 cysts were operated showed encouraging results as $94.7 \%$ of patients were normal without any recurrence after single operation.

Tuberculosis of larynx is the commonest granulomatous disease of larynx. In this study we had 2 cases of laryngeal tuberculosis. One case was secondary to pulmonary tuberculosis. Both patients were smokers. The main sites of involvement were true cords, arytenoids and epiglottis. Dysphonia is the main symptom and diagnosis was confirmed on direct laryngoscopy and biopsy and medical treatment was given which yielded relatively good outcome. This is in accordance with Chopra et al. who had 3 cases of tuberculosis of larynx, of which 2 were secondary to pulmonary tuberculosis ${ }^{[14]}$. The commonest site of origin of lesions was from true vocal cords. Nearly $95 \%$ of lesions were from true vocal cords. This is in accordance with Mahesh Chandra Hegde, M et al. who had 6 cases of laryngeal tuberculosis Nearly $93 \%$ of lesions were from true vocal cords. Arytenoids and epiglottis were the next common site $(15 \%)$. Except of 1 case all were secondary to pulmonary tuberculosis. Out of which only 2 patients were smokers3. Essadi et al. ${ }^{[15]}$ in their study of 15 cases of laryngeal tuberculosis observed dysphonia to be the main symptom and concluded that the diagnosis depends direct laryngoscopy and on biopsy and that medical treatment gives a good outcome.

In this study the common sites of laryngeal papilloma were the vocal cords, false cords, ventricle and the lingual surface of epiglottis. This is in accordance with study conducted by Kashima H, Leventhal et al. ${ }^{[16]}$ This indicates that respiratory papillomatosis has a predilection for the squamociliary junctions of the aerodigestive tract. All cases were managed by debulking using microdebrider, which yielded good outcomes. This is in concurrence with many papers and articles by Pasquale et al. study on recurrent respiratory papillomatosis ${ }^{[17]}$, who reported improved voice quality, less operating room time, less mucosal injury and cost benefit for the micro-debrider compared with the $\mathrm{CO} 2$ laser. Patel et al. and El-Bitar and Zalzal et al, ${ }^{[18,19]}$ also reported improved outcomes with an endoscopic microdebrider. Out of 11 patients, two cases underwent tracheostomy initially followed by surgery. Repeated debulking was done in three cases at an interval of one year. Advised consumption of cabbage juice or a diet high in cruciferous vegetables (e.g., cabbage, cauliflower, broccoli, Brussels sprouts) rich in indole-3-carbinol which had a favorable effect. This is similar to a small dietary study conducted at Long Island Jewish Hospital that showed promising results ${ }^{[20]}$.

All the clinically diagnosed cases were later confirmed by histopathology reports.

\section{Conclusion}

The benign laryngeal lesion produces symptoms which can vary from mild hoarseness to life-threatening stridor, creating a lot of mental and emotional tension in the patient and the family. Early diagnosis of the lesions can lead to effective management and good recovery. Micro laryngeal surgery and voice rest offer a cost effective, useful and safe method for management of benign laryngeal lesions. Multiple resections are typical of laryngeal papilloma. Micro debridement of laryngeal lesions, if necessary, tracheostomy is often preferred to laser therapy.

\section{References}

1. Kashima H, Shah F, Lyles A, et al. Factors in juvenile onset and adult-onset recurrent respiratory papillomatosis. Laryngoscope. 1992;102:9-13.

2. Shah KV, Stern WF, Shaf PK, et al. Risk factors for juvenile -onset recurrent respiratory papillomatosis. Pediatr Infect Dis J. 1998;17:372-376.

3. Pawan Singhal, et al. Benign tumors of the larynx: a clinical study of 50 cases. IJOL and Head \& Neck Surgery. 01. 2009;61(Suppl 1):26-30.

4. Strong MS, Vaughen CW. Vocal cord nodules and polyps. Laryngoscope. 1971;81:911-915

5. Baitha S, Raizada RM, Singh AKK, Puttewar MP, Chaturvedi VN. Clinical profi le of hoarseness of voice. Indian J Otolaryngol Head Neck Surg. 2002;54(1):1418.

6. Epstein SS, Winston P, Friedmann I. The vocal cord polyp. J Laryngol Otology. 1975;71:673-688.

7. Myerson MC. Benign tumors. In: The human larynx, Charles C Thomas Publisher, USA, 1964, 262-267.

8. Hegde MC, Kamath PM, Bhojwani K, Peter R, Babu PR. Benign lesions of the larynx: A clinical study, IJLO. 2005;57(1):35-38.

9. Asif Wani A, et al. Benign Mucosal Fold Lesion as a Cause of Hoarseness of Voice-A Clinical Study.Otolarynlogy. 2012;2:120.

10. New GB, Erich JB. Benign tumors of the larynx: a study of 722 cases. Arch Otolaryngol. 1938;28:841910.

11. Batra K, Motwani G, Sagar PC. Functional voice disorders and their occurrence in 100 patients of hoarseness as seen on fiberoptic laryngoscopy. Indian J Otolaryngol Head Neck Surg. 2004;56(2):91-95. 
12. Chagnon F, Stone RE Jr. Nodules and polyps. In: Brown WS, Vinson DP, Carry MA (eds) Organic voice disorders: assessment and treatment. Singular Pub. Group, San Diego. 1996.

13. Lowenthal G. The treatment of polypoid laryngitis. Laryngoscope, 1958, 1095-1103

14. Chopra H, et al. Indian J Otolaryngol Head Neck Surg. 1997;49:276-9.

15. Essad M, et al. Laryngeal tuberculosis: Apropos of 15 cases. Rev Laryngol Otol (Bord). 2001;122:125-8.

16. Kashima H, Mounts $\mathrm{P}$, Leventhal B, et al. Sites of predilection in recurrent respiratory papillomatosis. Ann Otol Rhinol Laryngol. 1993;102:580-583.

17. Pasquale K, Wiatrak B, Woolley A, Lewis L. Microdebrider versus $\mathrm{CO} 2$ laser removal of recurrent respiratory papillomatosis. Laryngoscope, 2003, 113139-143.

18. Patel N, Rowe M, Tunkel D. Treatment of recurrent respiratory papillomatosis in children with microdebrider. Arch Oto Rhino Laryngol. 2003;112:7103

19. El-Bitar MA, Zalzal GH. Powered instrumentation in the treatment of recurrent respiratory papillomatosis, an alternative to the $\mathrm{CO} 2$ laser. Arch Otolaryngol Head Neck Surg. 2002;128:425-428.

20. Rosen CA, Woodson GE, Thompson JW, et al. Preliminary results of the use of indole-3-carbinol for recurrent respiratory papillomatosis, Otolaryngol Head Neck Surg. 1998;118:810-815. 